\title{
Identificação de Enterobacteriaceae da microbiota intestinal de aves de postura (Gallus gallus Linnaeus, 1758) da linhagem Lohmann S.L.S.
}

\section{Enterobacteriaceae identification of the intestinal microbiota in laying hens (Gallus gallus Linnaeus, 1758) from Lohmann S.L.S. lineage}

\author{
Gicélia Maria da Silva, ${ }^{*}$ Cláudia Maria Ferreira da Silva, ${ }^{* *}$ Sávio Freire Bruno, ${ }^{* * *}$ Dayse Lima da Costa Abreu ${ }^{* \star * *}$
}

\begin{abstract}
Resumo
A utilização de antibióticos na avicultura, para o controle de doenças, tem causado alterações na microbiota normal do trato digestivo das aves, podendo causar o predomínio de espécies potencialmente patogênicas. O objetivo deste trabalho é o reconhecimento destas espécies e seu risco para a saúde pública. A microbiota intestinal de cem galinhas poedeiras comerciais da linhagem Lohmann S.L.S. foi estudada. Foram coletadas, por via cloacal, amostras fecais através de swabs estéreis e transportadas em tubos de ensaio contendo o meio Cary Blair, sendo posteriormente submetidas às técnicas bacteriológicas convencionais para isolamento e identificação dos gêneros. Foram utilizados os sistemas Bactray I e II, e o API - 20 E, para identificar as espécies. Os microrganismos isolados nos sistemas Bactray I e II foram: Escherichia coli (57\%), Arizona hinshawii (15\%), Serratia odorifera (8\%), Klebsiella oxytoca (3), Citrobacter freundii (3\%), Citrobacter diversus (8\%), Enterobacter sakazakii (3\%), Kluyvera sp (3\%); os resultados obtidos do sistema API-20E foram: Vibrio metschnikovii (29\%), Enterobacter cloaceae (13\%), Pantoea agglomerans (14\%), Citrobacter diversus (14\%), Escherichia coli (14\%), Burkholderia pseudomallei (14\%) e Citrobacter sp (2\%). A incidência de Arizona hinshawii foi significativa, sendo esta classificada na tribo Salmonelleae, mesma do gênero Salmonella, que tem sido referido como zoonose, justificando, assim, a importância do monitoramento das principais bactérias que compõem a microbiota intestinal.
\end{abstract}

Palavras-chave: galinhas, isolamento, enterobacteriaceae.

\begin{abstract}
The utilization of antibiotics in the avian industry to control diseases, have changed the normal intestinal microbiota, increasing the potential pathogenic species. The intention of this study is the recognition of this species and your public health risk. The intestinal microbiota of one hundred laying hens from commercial lineage Lohmann S.L.S. was studied. Feces were collected by cloacal drag-swab sampling and carried in sterile tube with Cary Blair medium and submitted to conventional bacteriology isolated and identified the bacterial genus. The Bactray I e II and API- 20E system were used to identify the species. The microorganisms verified in the Bactray I and II system were: Escherichia coli (57\%), Arizona hinshawii (15\%), Serratia odorifera $(8 \%)$, Klebsiella oxytoca (3\%), Citrobacter freundii (3\%), Citrobacter diversus (8\%), Enterobacter sakazakii (3\%), Kluyvera sp (3\%); the results in the API - 20E were: Vibrio metschnikovii (29\%), Enterobacter cloaceae (13\%), Pantoea agglomerans (14\%), Citrobacter diversus (14\%), Escherichia coli (14\%), Burkholderia pseudomallei (14\%) e Citrobacter sp (2\%). The incidence of Arizona hinshawii was significative. This specie is classified in the tribe Salmonelleae, the same of the genus Salmonella, refereed as a zoonosis, justifying the importance of the accompaniment of the principal species of normal intestinal microbiota in laying hens. The intent of this present study was evaluate the intestinal microbiota in the laying hens that can cause risks for the public health due the consume of the eggs in state of Rio de Janeiro.
\end{abstract}

Keywords: chicken, isolation, enterobacteriaceae.

\section{Introdução}

O estudo da microbiota intestinal tem sido motivo de diversas investigações científicas, principalmente pelo relacionamento que se estabelece entre o hospedeiro e os organismos que ele alberga. March (1979) relatou que uma das funções da microbiota intestinal das aves é a produção de vitamina $\mathrm{Ke}$ do complexo $B$, que mantém o equilíbrio da mesma. Considerou ainda que, possivelmente pequenas concentrações de bactérias patogênicas constituiriam parte da microbiota intestinal, não determinando, contudo, infecções, salvo sob a influência de fatores estressantes que,

\footnotetext{
* Professora, Dra., responsável pela disciplina de Ornitopatologia, Faculdade de Veterinária da Universidade Federal Fluminense, Rua Vital Brazil Filho, 64 - Cx. Postal 100 - 086, CEP 24230-340 - Niterói, RJ.

** Graduanda em Medicina Veterinária, Faculdade de Veterinária da Universidade Federal Fluminense.

*** Professor, Dr., adjunto II, da disciplina de Animais Silvestres, Faculdade de Veterinária da Universidade Federal Fluminense.

**** Professora, MS, da disciplina de Ornitopatologia, Faculdade de Veterinária da Universidade Federal Fluminense.
} 
de acordo com Miles et al. (1981), são, sob suas diversas formas, responsáveis por alterações na microbiota intestinal e consequentemente predomínio de uma sobre as outras. Manning et al. (1994) observaram que o uso de antimicrobianos pode reduzir ou eliminar salmonelas, ou ainda aumentar a susceptibilidade à recontaminação, mas também, de acordo com Reynolds et al. (1997) pode exacerbar a população de outras enterobacteriaceas devido ao desequilíbrio da microbiota normal do intestino. Nisbet et al. (1993) isolaram bactérias Gram-positivas e negativas da microbiota cecal de frangos de corte entre as quais destacaram o Enterococcus faecalis, a Escherichia colie Escherichia fergusoni, como causadores de grandes modificações na microbiota intestinal das aves. Miyamoto et al. (1998), relataram que houve predominância de Bacteroidaceae, Lactobacillus e Escherichia coli na microbiota da cloaca e oviduto em galinhas.

As aves possuem um mecanismo natural de proteção do trato digestivo constituído pela microbiota normal do intestino, principalmente a anaeróbia, que produz metabólitos como os ácidos graxos voláteis e as bacteriocininas, que estabelecem um mecanismo de competição. Essa microbiota tem sido usada na alimentação de aves associado ou não à lactose (Scholtyssek, 1991; Silva, 1995). O uso de microbiota cecal passada em frangos de engorda alimentados com lactose preservou a microbiota protetora em pintos de engorda segundo Ziprin et al. (1993).

Harry (1963), em suas pesquisas em aves poedeiras, observou que os microrganismos presentes na cloaca poderiam contaminar o oviduto das mesmas. Garibaldi e Stolkes (1958) e Haines e Moran (1940), reportaram que a casca do ovo é permeável a microrganismos tais como: Escherichia coli, Salmonella paratyphi, Serratia marcescens e Pseudomonas aeruginosa. Myiamoto et al. (1998), em estudos experimentais com Salmonella enteriridis, descrevem a possibilidade deste microrganismo ascender para partes mais altas do oviduto, com subseqüente contaminação do ovo.

O objetivo deste estudo foi avaliar a prevalência das enterobacteriaceas da microbiota intestinal das aves poedeiras, criadas nos sistemas convencionais que possam causar problemas na saúde pública.

\section{Material e métodos}

Foram utilizadas cem aves de postura comercial da linhagem Lohmann S.L.S., escolhidas aleatoriamente, provenientes de granja localizada no município de São José do Vale do Rio Preto, estado do Rio de Janeiro. As aves eram criadas em gaiolas, recebendo água ad libitum e ração fabricada na própria granja. Foram coletadas amostras fecais, via cloacal, com o auxílio de swabs estéreis. Os swabs foram acondicionados em tubos de ensaio esterilizados, contendo o meio "Cary-Blair" (meio de transporte) e enviados para o laboratório de Ornitopatologia da Faculdade de Veterinária - UFF, onde foram refrigerados e processados no dia seguinte. As amostras foram semeadas em água peptonada para pré-enriquecimento e depois repassados para os caldos tetrationato, selenito e $\mathrm{BH}$ (infusão de cérebro e coração) para enriquecimento seletivo. Para o plaqueamento, foram utilizados os meios ágar verde brilhante, ágar Salmonella-Shigella, ágar Levine e ágar eosina e azul de metileno-Teague quando alíquotas dos caldos tetrationato, selenito e BHI foram transferidas paras esses meios. As placas foram incubadas em estufa a $37^{\circ} \mathrm{C}$ por 24 horas em aerobiose. Após a incubação, as placas foram observadas para a visualização das unidades formadoras de colônias (UFCs) e coletadas de duas a três UFCs de cada placa com o auxílio de agulha de platina e colocadas em tubos diferentes contendo $2 \mathrm{ml}$ de Caldo $\mathrm{BHI}$ (Laboratório Difco). Cada amostra foi levada à estufa a $37^{\circ} \mathrm{C}$ por 24 horas. A seguir procedeu-se à coleta das amostras contidas no Caldo $\mathrm{BHI}$, com o auxílio de alça bacteriológica, para a semeadura de placas contendo o ágar de eosina e azul de metileno. As placas, após semeadas, foram incubadas a $37^{\circ} \mathrm{C}$ por 24 horas em aerobiose. Das UFCs que se apresentaram no ágar de eosina e azul de metileno, duas a três eram retiradas com agulha bacteriológica e colocadas em meio de Costa-Vernin. Após a inoculação procedeu-se à incubação do material a $37^{\circ} \mathrm{C}$ por 24 - 48 horas. Este procedimento permitiu uma identificação presuntiva através da análise da motilidade, ação sobre a lactose/sacarose, produção de gás, produção de gás sulfídrico, ação da urease e produção do indol. As diferentes amostras retiradas do meio Costa-Vernin foram submetidas a análise bioquímica através dos sistemas Bactray I e II e API-20E para identificação das espécies. Convém esclarecer que a utilização dos sistemas de identificação de enterobacteriaceae não objetivou a comparação dos resultados dos mesmos, pois as cepas inoculadas foram de colônias diferentes. As técnicas de isolamento seguiram os métodos de Hofer e Costa (1972); Bier (1984); Board (1985); Ewing e Edwards (1986); Ferket (1991); Silva (1995) e Assumpção e Silva (1996).

\section{Resultados e discussão}

Das cem amostras bacterianas utilizadas de 100 aves de postura da linhagem Lohmann SLS, foram identificadas através dos sistemas Bactray I e II as espécies: Escherichia coli, Arizona Hinshawii, Serratia odorífera, Klebsiela oxytoca, Citrobacter freundii, Citrobacter diversus, Enterobacter sakazakii, Kluyvera $s p$., e os percentuais relativos as mesmas foram respectivamente: $57 \%$, 15\%, 8\%, 3\%, 3\%, 8\%, 3\% e 3\%.

Tabela 1: Identificação das amostras bacterianas isoladas de 100 aves de postura saudáveis da linhagem Lohmann SLS através dos sistemas Bactray I e II

\begin{tabular}{l|c}
\hline \multicolumn{1}{c|}{ Amostras bacterianas } & Percentual (\%) \\
\hline Escherichia coli & $57 \%$ \\
Arizona hinshawii & $15 \%$ \\
Serratia odorifera & $8 \%$ \\
Klebsiella oxytoca & $3 \%$ \\
Citrobacter freundii & $3 \%$ \\
Citrobacter diversus & $8 \%$ \\
Enterobacter sakazakii & $3 \%$ \\
Kluyvera sp & $3 \%$ \\
\hline
\end{tabular}

Das 100 amostras bacterianas utilizadas de 100 aves de postura da linhagem Lohmann SLS, foram identificadas através dos sistemas API 20E as espécies: Vibrio metschnikovii, Pantoea aglomerans, Citrobacter diversus, Escherichia coli, Burkholderia Pseudomallei, Enterobacter cloaceae e Citrobacter sp., e os percentuais relativos às mesmas foram respectivamente: $29 \%, 14 \%, 14 \%, 14 \%, 14 \%, 13 \%$ e $2 \%$. 
Tabela 2: Identificação das amostras bacterianas isoladas de 100 aves de postura saudáveis da linhagem Lohmann SLS através do sistema API 20E

\begin{tabular}{l|c}
\hline \multicolumn{1}{c|}{ Amostras bacterianas } & Percentual (\%) \\
\hline Vibrio metschnikovii & $29 \%$ \\
Pantoea agglomerans & $14 \%$ \\
Citrobacter diversus & $14 \%$ \\
Escherichia coli & $14 \%$ \\
Burkholderia pseudomallei & $14 \%$ \\
Enterobacter cloaceae & $13 \%$ \\
Citrobacter sp & $2 \%$ \\
\hline
\end{tabular}

Dentre as bactérias isoladas, muitas são reconhecidamente patogênicas como a Escherichia coli e a Arizona hinshawii, constituindo-se, assim, em importante achado em Ornitopatologia. Tal aspecto é confirmado com os trabalhos de Hofer e Costa (1972) que sugerem a presença dos gêneros Klebsiella, Citrobacter e Enterobacter, que podem ser responsabilizadas como agentes de vários processos patológicos o que se comprova com os achados do presente trabalho. Em estudos desenvolvidos por Abreu et al. (1999) onde ocorreu a inoculação experimental, em pintos de 1 dia, o gênero Citrobacter causou lesões anatomopatológicas em vários órgãos, mostrando a importância do gênero relacionado com processos infecciosos. Haines e Moran (1940) citaram que Escherichia coli, Salmonella paratyphi, Serratia

\section{Referências}

ABREU, D. L. C.; SILVA, G. M.; MEDEIROS, M. I. M.; COSTA, C. H. C. Achados patológicos em pintos de 1 dia após inoculação experimental com salmonella pullorum, salmonella arizonae e Citrobacter diversus. Rev. Bras. Ciênc. Vet. v. 6, n. 3, 1999.

API20E. CATALOGUE ANALYTIQUE. CopyrightBIO MÉRIEUXS.A. 3. ed. Mars 1994, $443 p$.

ASSUMPÇÃO, R. B; SILVA, G. M. Estudo da microflora (Enterobacteriaceae gram-negativa) em pintos de um dia de idade (Gallus gallus Linnaeus, 1758) apresentando um quadro de onfalite. 57 p. Monografia (Graduação)-Faculdade de Veterinária Universidade Federal Fluminense, 1996.

BAC-TRAY I II. SISTEMA DE IDENTIFICACÃO DE BACTÉRIAS GRAM NEGATIVAS OXIDASE NEGATIVA. CATALOGUE ANALYTIQUE. Laboratórios DIFCO Ltda. Ano 1984, p. 1014.

BIER, O. Microbiologia e imunologia. 4. ed. São Paulo: Melhoramentos, 1984.

BOARD, R. G. The microbiology of hen's egg. Bacteriologie, v. 28, p. 245-281, 1985.

EWING, W. H.; EDWARDS, E. Idendifications of enterobacteriaceae. 4. ed. New York: Elsevier, 1986.

FERKET, P. R. Effect of diet on gut microflora of poultry. Zootecnia Internacional, v. 22, p. 44-49, 1991.

GARIBALDI, J. A.; STOLKES, J. L. Protective role of shell membranes in bacterial spoilage of eggs. Food Res., v. 23, p. 283-298, 1958.

HAINES, R. B.; MORAN, T. Sorosity and bacterial invasion through the shell of hen's egg. The Journal of Hygierne, v. 40, p. 63-70, 1940.

HARRY, E. G. Some observations on the bacterial content of the ovary and oviduct of the fowl. Britsh Poultry Science, n. 4, p. 63-70, 1963. HOFER, E.; COSTA, R. A. Isolamento e identificação de enterobacterias (Apostila). Rio de Janeiro: Instituto Oswaldo Cruz, 1972, 120 p. marcenscens e Pseudomonas aeruginosa, como causadoras de sérios problemas à saúde humana. Seus achados, quando comparados com os resultados desta pesquisa, mostram que as aves podem-se tornar portadoras destes microrganismos, o que possivelmente poderá ocasionar contaminação vertical, através de ovos, ou horizontal ao plantel e até mesmo aos consumidores de aves ou de seus ovos. Entretanto, os percentuais de Escherichia coli neste trabalho foi de $57 \%$, demonstrando que este número pode ser sugestivo de contaminação no plantel.

\section{Conclusão}

Do ponto de vista sanitário, observou-se neste trabalho que as instalações das aves poedeiras eram boas e que o isolamento das bactérias poderia ser atribuído a alguns fatores extrínsecos não evidenciados, embora tenha-se encontrado um percentual considerável de Escherichia coli (57\%), que sugere que a água de abastecimento possa ser um dos fatores a ser considerado. De acordo com Saxena (1992), a contaminação da água é um dos principais fatores na prevalência da colibacilose aviária. Quanto à distribuição de ração, preconiza-se um rigoroso controle de qualidade, pois esta pode ser, de acordo com Patnaick (1986), responsável por variadas formas de infecção, caso não possuam origem idônea. Tais cuidados minimizam consideravelmente os riscos à saúde do consumidor no que diz respeito, principalmente, às enfermidades transmitidas por alimentos (ETA).

MANNING,J. G.;HARGIS, B. M.; HINTON, A.;CORRIER, D. E.; DeLOACH, J. R.; CREGER, C. R. Effect of selectd antibitics and anticoccidials on Salmonella enteritidis cecal colonization and organ invasion in Leghorn chicks. Avian diseases, v. 38, n. 2, p. 256-261, 1994.

$\mathrm{MARCH}, \mathrm{B}$. E. The host and its microflora and ecological unit. Journal of Animal Science, v. 49, n. 3. 1979.

MILES, R. D.; ARAFA, A. S.; HARMS, R. A.; CARLSON, C. W.; REID, B. L.; CRAWFORD, J. S. Living nonfeeze - dried Lactobacillus culture on performance, egg quality and gut microflora in commercial layers. Poultry Science, v. 60, p. 993-1004, 1981.

MYIAMOTO, T.; HORIE T.; FUKATA, T.; SASAIK.; BABA, E. Changes in microflora of the cloaca and oviduct of hens aftter intracloacal or intavaginal inoculaton with salmonella enteritidis. Avian diseases v. 42, n. 3, p. 536-544, 1998.

NISBET, D. J.; CORRIER, D. E.; SCANLAN, C. M.; HOLLISTER, A.G.; BIERER, R. C.; DeLOACH, J. R. Effect of a detnet flow derred bacterial culture and dietary lactose on Salmonella typhimurium colonization in broiler chickens. Avian Diseases, n. 37, p. 1017-1025, 1993.

PATNAICK, R. B.; PANDA, S. N. Bacterial isolates from poultry in Orissa in India. Journal of Poultry Science, n. 21, p. 110-113, 1986.

REYNOLDS, D. J.; DAVIES, R. H.; RICHARDS, M. E.;WRAY, C. Evaluation of combined antibiotic and competitive exclusion treatment in broiler breeder flocks infected whith Salmonella enterica serovar enteritidis. Avian pathology, v. 26, n. 1, p. 83-95, 1997.

SAXENA, H. C. The major problems on poultry farms in India. Colibacilosis and mycotoxicosis. Misset - World Poultry, n. 8, p. 3-47, 1992.

SCHOLTYSSEK, S. The future of egg marketing depends on quality assurence. Misset-World Poultry, v.7, n. 4, p. 29-31, 1991.

SILVA, E. N. Salmonella enteritidis em aves e Saúde Pública. Higiene alimentar, v. 9 n. 37, p. 7-13, 1995.

ZIPRIN, R.L.; CORRIER, D. E. E.; DeLOACH, J. R. Control of stablished salmonella thiphimurium intestinal colonization with in vivo-passaged anaerobes. Avian diseases, v. 37, p. 138-188,1993. 